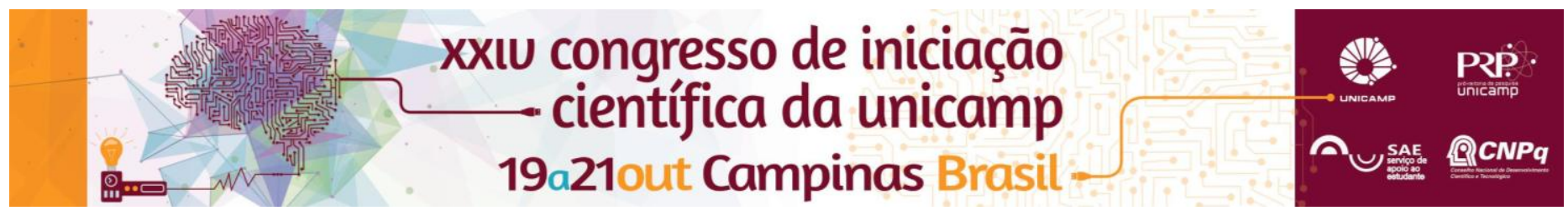

\title{
Análise dos financiamentos das interações universidade-empresa no Brasil
}

\author{
Erika Miyazaki*, Renato Garcia.
}

\begin{abstract}
Resumo
O projeto tem como objetivo principal a análise da importância da universidade e dos institutos públicos de pesquisa para o suporte aos processos de geração e difusão de inovações na indústria brasileira. Para isso, serão analisados os programas de apoio às atividades inovativas das empresas, por meio do levantamento das informações sobre os financiamentos das interações universidade-empresa, a partir dos dados do Diretório dos Grupos de Pesquisa CNPq.
\end{abstract}

\section{Palavras-chave \\ Economia da inovação, interação universidade-empresa, conhecimento e inovação.}

\section{Introdução}

Inovação é o termo utilizado para se descrever um conjunto de processos e que resultam na elaboração de novos ou melhorados produtos ou na pioneira utilização de novos ou melhorados processos. Como possibilita ganhos de eficiência no sistema, a inovação permite obter melhores resultados com menor uso de recursos. Por isso, tem sido um objeto de interesse crescente de estudiosos com o objetivo de compreender o processo de geração e difusão de inovações entre os agentes econômicos.

Costuma-se dividir os papéis de realizador de pesquisa básica e desenvolvimento tecnológico entre universidade e empresa, respectivamente. Contudo, é a consolidação de um vínculo entre uma tecnologia e um campo da ciência que torna intensa a atividade científica nesse campo. Portanto, a relação universidade-empresa é fundamental no sucesso do processo de desenvolvimento de uma inovação.

O objetivo principal deste trabalho é a análise do financiamento nas interações entre universidades e grupos de pesquisa com as empresas (UE) através da base de dados coletados no Diretório de Grupos de Pesquisa do CNPq. Esta análise é feita com a associação dos resultados mais importantes identificados da base de dados com um levantamento bibliográfico sobre o tema.

\section{Resultados e Discussão}

É difícil determinar tanto as causas e motivações como as consequências nos âmbitos econômico e social de uma inovação. Isso pode ser explicado pelo fato dos aperfeiçoamentos tecnológicos nem sempre penetrarem a estrutura econômica de uma forma visível e evidente. Por isso, o estudo do processo de inovação deve ter uma abordagem sistêmica. É preciso entender a origem de uma inovação e o ambiente onde esse desenvolvimento ocorre. As universidades e institutos públicos de pesquisa exercem papel fundamental no apoio ao desenvolvimento científico e tecnológico. Portanto, a relação UE é fundamental no sucesso do processo de desenvolvimento de uma inovação.

Assim, este trabalho consiste na análise da relação UE através de uma base de dados do CNPq, coletada em esforço conjunto de diversos pesquisadores, para este fim. Foi utilizada a base censitária de 2010 e foram coletados os dados de 27.495 grupos de pesquisa científica e tecnológica em atividade no país, localizados, principalmente, em universidades, instituições isoladas de ensino superior com cursos de pós-graduação stricto sensu, institutos de pesquisa científica e institutos tecnológicos; e 4.740 instituições parceiras, com as quais os grupos informam possuir algum tipo de relacionamento, resultando em 7.071 interações.

Foi possível analisar quais os tipos de relacionamentos existentes entre grupos de pesquisa e instituições e a forma genérica de remuneração dessas relações, categorizados em 14 tipos mais habituais de relacionamento e 10 os modos mais habituais de remuneração. Para melhor visualização, agrupamos essas variações em três grandes categorias cada.

Os tipos de interação foram separados em pesquisa, transferências e treinamento ou consultoria. O tipo mais utilizado foi o de pesquisa, com mais de $60 \%$ dos resultados observados. Os tipos de remuneração foram separados em bolsa, insumos e recursos, sendo que o mais utilizado foram os recursos, com mais de $50 \%$ da participação.

A colocalização também foi analisada, de modo preliminar, de forma que foi possível perceber uma relação mais intensa com empresas geograficamente mais próximas aos grupos de pesquisa.

\section{Conclusões}

A análise em geral permitiu realizar uma análise descritiva e identificar o perfil de interação geral entre as universidades e as empresas. Contudo, um problema identificado é a possibilidade de dupla contagem, pelo fato da maior parte das empresas declararem utilizar mais de um tipo de interação e remuneração.

De qualquer modo, foi possível observar a importância do papel da universidade no desenvolvimento de inovações nas instituições. A remuneração mais utilizada, por transferência de recursos financeiros ao grupo, pôde ser relacionada à interação mais comum, por meio de pesquisa, através da caracterização dos grupos e das suas interações.

Rosenberg, N. 1982. Inside the Black Box: Technology and Economics. Cambridge University Press.

Nelson, R. R. 1996. The Sources of Economic Growth. Cambridge: Harvard University Press

Mowery, D. C., R. R. Nelson, B. N. Sampat, A. A. Ziedonis. 2004. Ivory Tower and Industrial Innovation - University-Industry Technology Transfer Before and After the Bayh-Dole Act. Stanford University Press.

Mowery, D.C, B.N. Sampat. 2005. Universities in national innovation systems. In: Fagerberg J, Mowery DC, Nelson RR (editors). The Oxford handbook on innovation. New York: Oxford University Press. pp. 209-239. 